\title{
Gastrointestinal duvar kalınlığına yaklaşım: Prospektif tek merkezli çalışma
}

\author{
Clinical approach to gastrointestinal wall thickening: A prospective single center study
}

\author{
Bilal ERGÜL, Levent FILIK \\ Ankara Eğitim ve Araștırma Hastanesi, Gastronenteroloji Kliniği, Ankara
}

\begin{abstract}
Giriş ve Amaç: Çeşitli abdominal şikayetler ile başvuran hastalarda ultrasonografi ve bilgisayarlı tomografi yaygin olarak kullanılmaktadır. Radyolojik yöntemlerde saptanan gastrointestinal sisteme ait duvar kalınlaşması saptanan olgularda yaklaşım ve algoritma ile ilgili ortak kabul görmüs bir konsensus yoktur. Gereç ve Yöntem: Ocak 2010- Temmuz 2012 tarihleri arasında Ankara Eğitim ve Araştırma Hastanesi Gastroenteroloji Bölümünde, herhangi bir nedenden dolayı abdominal ultrasonografi veya bilgisayarlı tomografi çekilen ve gastrointestinal sistem luminal kalınlaşma rapor edilerek endoskopi veya kolonoskopi yapılan hastalarnn verileri prospektif olarak toplandı. Hastaların yaşlan, cinsiyetleri, hematolojik parametreleri, radyolojik incelemedeki kalınlaşma tespit edilen bölgenin lokalizasyonu, endoskopi ve kolonoskopi bulguları, patoloji sonuçları ve elde edilen tanıları not edildi. Bulgular: Gastrointestinal sistem duvar kalınlğı saptanan ve takibinde endoskopik inceleme yapılabilen toplam 129 hasta (49 erkek, 80 kadın) çalışmaya dahil edildi. Hastaların ortalama yaşı $59.78(20-90, \pm 16.13)$ idi. Ortalama hemoglobin düzeyi $12.31 \mathrm{mg} / \mathrm{dl}(5.8-16.9, \pm 2.35)$ olarak bulundu. 60 hastada üst gastrointestinal sistem (özofagus, mide), 69 hastada ise alt gastrointestinal sistem (ileum, kolon) duvar kalınlığ saptandı. Üst gastrointestinal sistemde duvar kalınlığı saptanan hastalarnn 17'sinde (\%28.3), alt gastrointestinal sistemdekilerin ise 32'sinde (\%46.4) malign hastalıklar saptand.. Mide adenokarsinomlarının \%92.9'u (13/14), kolorektal adenokarsinomlarinın \%96.9'u (31/32) 50 yaşın üzerindeydi. Hemoglobin düzeyi 12.0 mg/dl'nin altında olan olgular incelendiğinde, üst gastrointestinal sistem duvar kalınlğı saptananların \% 73,3'ünde, alt gastrointestinal sisteme ait duvar kalınlığı saptananlarn \%72.3'ünde adenokarsinom tespit edilmiştir. Sonuç: Gastrointestinal sistem duvar kalınlığı önemli bir radyolojik bulgu olup özellikle 50 yaşın üzerinde ve hemoglobin düzeyi 12'nin altında olan hastalarda neoplastik hastalıkların ilk bulgusu olabilir. Radyolojik yöntemlerde gastrointestinal sistem duvar kalınlığı saptanan hastalara mutlaka endoskopik değerlendirme önerilmelidir.
\end{abstract}

Anahtar kelimeler: Gastrointestinal duvar kalınlașması, endoskopi, kolonoskopi, adenokarsinom

\section{GİRIS}

Günümüzde çeşitli abdominal şikayetler ile başvuran hastalarda ultrasonografi (USG) ve bilgisayarlı tomografinin (BT) yaygın olarak kullanılması sonucunda gastrointestinal sisteme (GIS) ait duvar kalınlaşması bulgusu ile sıklıkla karşılaşılmaktadır (1,2). Bu bulgunun normalin varyantı, benign veya malign hastalıkların bir göstergesi olabileceği tüm hekimler tarafindan düşünülmekte ve bu amaçla endoskopi ve kolonoskopi gibi daha ileri incelemeler yapılmaktadır. Endoskopik incelemelere bağlı gelişebilecek komplikasyonların riski ve maliyetlerdeki artış, bu işlemlerin ne kadar gerekli olduğu konusundaki sorgulamalara neden olmaktadır. Gastrointestinal sistemdeki duvar kalınlığı, lokalizasyona göre farklı değerlen-
Background and Aims: Computerized tomography and ultrasonography are frequently performed for a variety of abdominal complaints. Clinical guidelines are lacking regarding endoscopic procedures when gastrointestinal luminal wall thickening is reported on radiologic procedures. Materials and Methods: A prospective study was done from January 2010 to July 2012 on patients referred to the Gastroenterology Department of Ankara Education and Research Hospital for incidental gastrointestinal luminal wall thickening on computerized tomography and ultrasonography during the study period. Age, gender, radiologic abnormality and thickening location, endoscopic findings, hematologic parameters, and pathologic data were collected. Results: 129 patients (80 female, 49 male) with gastrointestinal wall thickening who proceeded to endoscopy were identified. The average age of the patients was 20-90 years (mean, 59.78 years). Gastrointestinal luminal wall thickenings were distributed along the gastrointestinal tract as follows: 60 upper (esophageal, gastric, and duodenum) and 52 lower (colon and ileum). Seventeen (28.3\%) of the upper gastrointestinal and 32 (46.4\%) of the lower gastrointestinal tract wall thickenings were malignant conditions. 92.9\% (13/14) of patients with gastric adenocarcinoma and $96.9 \%$ (31/32) of patients with colorectal adenocarcinoma were older than 50 years. $73.3 \%$ of patients with a hemoglobin level less than $12 \mathrm{mg} / \mathrm{dl}$ had neoplastic findings in the upper gastrointestinal tract and $72.3 \%$ in the lower gastrointestinal tract. Conclusions: We conclude that gastrointestinal luminal wall thickening is an important radiologic finding and could be the initial presentation of malignancy, particularly in patients older than 50 and with hemoglobin level less than $12 \mathrm{mg} / \mathrm{dl}$. Endoscopic evaluation should be strongly recommended in patients with gastrointestinal luminal wall thickening determined on radiologic procedures.

Key words: Gastrointestinal luminal wall thickening, endoscopy, colonoscopy, adenocarcinoma

dirilmekle birlikte birçok faktör tarafından etkilenebilmektedir. Luminal distansiyona, alınan oral kontrastın lümeni homojen doldurmamasına veya lümende birikmiş gıda parçalarl, feçes, hava veya sıvıya bağlı olarak radyolojik incelemelerde yanlış duvar kalınlaşması tespit edilebilir. Bununla birlikte eşlik eden siroz, kalp yetmezliği, hipoalbuminemi gibi hastalıklarda intestinal duvardaki ödeme bağlı olarak duvarda kalınlaşma saptanabilir (1). GIS duvar kalınlığı saptanan olgulardaki endoskopik bulguları inceleyen az sayıda çalışma mevcuttur $(3,4)$. Ancak, halen GIS duvar kalınlaşması saptanan olgularda yaklaşım ve algoritma ile ilgili ortak kabul görmüş bir konsensus yoktur. 
Bu çalışmada transabdominal USG veya BT'de özofagus-mide-ince barsaklar veya kolonda duvar kalınlaşması saptanan olgulardaki endoskopik bulguları, duvar kalınlığı ve bazı hematolojik parametreler ile saptanan bulguların ilişkisini incelemeyi amaçladık.

\section{GEREÇ VE YÖNTEM}

Ocak 2010- Temmuz 2012 tarihleri arasında Ankara Eğitim ve Araştırma Hastanesi Gastroenteroloji Bölümünde, herhangi bir nedenden dolayı abdominal USG veya BT çekilen ve GIS luminal kalınlaşma rapor edilerek endoskopi veya kolonoskopi yapilan hastaların verileri prospektif olarak toplandı. Duvar kalınlığında artış, mide ve özofagus için $5 \mathrm{~mm}$ ve üzeri, ileum ve kolon için $3 \mathrm{~mm}$ ve üzeri, rektum için ise $5 \mathrm{~mm}$ ve üzeri olarak belirlendi (5). Terminal ileumda duvar kalınlaşması saptanan olgularda kolonoskopi ile birlikte terminal ileum entubasyonu yapılarak bu bölgenin de değerlendirilmesi yapıldı. Hastaların yaşları, cinsiyetleri, hematolojik parametreleri, radyolojik incelemedeki kalınlaşma tespit edilen bölgenin lokalizasyonu, endoskopi ve kolonoskopi bulguları, endoskopik inceleme esnasında alındıysa patoloji sonuçları ve elde edilen tanıları not edildi. Daha önceden bilinen gastrointestinal sisteme ait kanser veya kronik inflamatuvar hastalığı olanlar, kalp yetmezliği, kronik karaciğer hastalığı, hipoalbuminemi, nefrotik sendromu olanlar, kolonoskopik inceleme yapilan ancak yetersiz temizlik veya hasta intoleransı nedeniyle işlemin optimal olmadığı vakalar çalışma dışı bırakildi.

Çalışmadaki verilerin analizinde SPSS 15.0 for Windows (SPSS, Inc, Chicago, IL, USA) programı kulanılmıştır. Verileri değerlendirilmesinde tanımlayıcı istatistiksel yöntemlerin yanı sıra grupların karşılaştırılması için student-t testi, Ki-kare testi, Mann-Whitney U testi ve Kruskal-Wallis varyans analizi kullanılmıştır. Yüzde 95 güven aralığında ve $p<0.05$ sonuçlar anlamlı olarak kabul edildi.

\section{BULGULAR}

GIS duvar kalınlığı saptanan ve yeterli endoskopik inceleme yapılabilen toplam 129 hasta (49 erkek, 80 kadın) çalışmaya dahil edildi. Hastaların ortalama yaşı 59.78 (20-90,_16.13) idi. Ortalama hemoglobin düzeyi $12.31 \mathrm{mg} / \mathrm{dl}$ (5.8-16.9, \pm 2.35 ) olarak bulundu. 60 hastada üst GİS (özofagus, mide), 69 hastada ise alt GIS (ileum, kolon) duvar kalınlığı saptandı. GIS duvar kalınlığı saptanan bölgelerin ayrıntılı dağılımı Tablo l'de görülmektedir.

Mide duvar kalınlığı saptanan toplam 60 olgunun 36'sında (\%60) gastrit saptanırken 14 hastada $(\% 23,3)$ adenokarsinom tespit edildi. Üst GIS endoskopisi yapilan bu 60 olguda saptanan bulgular Tablo 2'de ayrıntılı olarak görülmektedir. Tanısı gastrit olanların radyolojik olarak mide duvar kalınlığı ortanca 8 mm (5-24), ülser tanısı alanlarda ortanca 10 mm (7-
13), karsinom saptanan olgularda ise ortanca $15 \mathrm{~mm}$ (8-33 $\mathrm{mm}$ ) olarak saptandı $(\mathrm{p}<0.001)$.

Alt GIS'e ait duvar kalınlığ saptanan toplam 69 hastanın 32 'sinde $(\% 46,4)$ adenokarsinom, 12'sinde (\%17,4) Crohn hastalığı, 10'unda (\%14,5) polip, 2'sinde $(\% 2,9)$ non-spesifik kolit, l'inde $(\% 1,4)$ ülseratif kolit tespit edilirken, sadece 12 hastada $(\% 17,4)$ herhangi bir patoloji saptanmadı (Tablo 3). Radyolojik olarak saptanan duvar kalınlığı, normal kolonoskopik bulgusu olanlarda ortanca $8 \mathrm{~mm}$ (5-21 mm), polip saptananlarda $10 \mathrm{~mm}$ (7-24 mm), Crohn hastalığı tanısı alanlarda $11.5 \mathrm{~mm}$ ( 6-20 mm), adenokarsinom saptananlarda ise ortanca $15 \mathrm{~mm}(6-27 \mathrm{~mm})$ olarak bulundu $(\mathrm{p}<0.001)$.

Hb düzeyi 12.0 mg/dl'nin altında olan olgular incelendiğinde; mide duvar kalınlığı saptananların \%73,3'ünde malign hastalıklar saptanırken, alt GİS'e ait duvar kalınlığı saptananların

$\begin{array}{lcc}\text { Tablo 1. Radyolojik olarak duvar kalınlığı saptanan bölge- } \\ \text { lerin dağılımı } \\ \text { Kalınlık lokalizasyonu } & \text { Sayı } & \text { Yüzde } \\ \text { Mide } & 60 & 46.5 \\ \text { lleum } & 7 & 5.4 \\ \text { Çıkan kolon } & 19 & 14.7 \\ \text { Transvers kolon } & 7 & 5.4 \\ \text { Inen kolon } & 10 & 7.8 \\ \text { Rektosigmoid } & 26 & 20.2 \\ \text { Toplam } & 129 & 100\end{array}$

Tablo 2. Üst GIS' de duvar kalınlığı saptanan olguların endoskopik bulguları

$\begin{array}{lcc}\text { Tanı } & \text { Sayı } & \text { Yüzde } \\ \text { Gastrit } & 36 & 60,0 \\ \text { Adenokarsinom } & 14 & 23,3 \\ \text { Gastrik ülser } & 5 & 8,3 \\ \text { Lenfoma } & 3 & 5,0 \\ \text { Gastrik polip } & 1 & 1,7 \\ \text { Leiomyom } & 1 & 1,7 \\ \text { Toplam } & 60 & 100,0\end{array}$

\begin{tabular}{lcc}
$\begin{array}{l}\text { Tablo 3. Alt GíS' de duvar kalınlığı saptanan olguların en- } \\
\text { doskopik bulguları }\end{array}$ & \multicolumn{3}{c}{ Sayı } & Yüzde \\
Tanı & 32 & 46,4 \\
Adenokarsinom & 12 & 17,4 \\
Normal & 12 & 17,4 \\
Crohn Hastalı̆ı & 10 & 14,5 \\
Polip-adenom & 2 & 2,9 \\
Non-spesifik kolit & 1 & 1,4 \\
Ülseratif Kolit & 69 & 100,0 \\
Toplam &
\end{tabular}


\%72.3'ünde adenokarsinom, \% 12.1'inde inflamatuvar barsak hastalıkları tespit edilmiştir.

Midede adenokarsinom tespit edilen hastaların \%92.9'ü (13/14) 50 yaşın üzerinde iken, kolonda bu oran \%96.9 (31/32) olarak bulundu.

\section{TARTIȘMA}

Bu çalışmada üst gastrointestinal sitemde duvar kalınlığı saptanan olguların \%28'inde, alt GIS’teki duvar kalınlığı olgularının ise \%46'sında altta yatan bir malignite tespit edildi. Tüm hasta grubunda ise GIS'e ait malignite saptanma oranı \%37.9 olarak bulundu. Hb düzeyi 12'nin altında olan vakaların yaklaşık 3/4’ünde malignite saptandı. Duvar kalınlığı arttıkça, benign patolojilerden malign oluşumlara doğru görülme sıklı̆̆ artmaktaydl. Adenokarsinom saptanan vakaların neredeyse tamamı 50 yaşın üzerindeydi

Literatürde radyolojik incelemeler esnasinda saptanan intestinal duvar kalınlığının endoskopik incelemeler ile birlikte değerlendirildiği az sayıda çalışma mevcut olup vaka sayısı bizim çalışmamıza göre daha azdır. Cai ve arkadaşlarının 67 hastalık serisinde vakaların \%70'inde endoskopik anormallik saptanırken sadece 4 vakada kanser tespit edilmiştir (2). En geniş hasta grubu 50 vakadan oluşan diğer 3 çalışmada ise kanser saptanma oranları \%12, \%23 ve \%29 olarak bulunmuştur (4-6).

Sadece kolon duvar kalınlığının endoskopik inceleme ile klinik öneminin incelendiği birkaç çalışma mevcuttur. Wolfhh ve arkadaşlarının karın ağrısı şikayeti ile başvuran ve çekilen abdominal BT'de kolon duvar kalınlaşması tespit edilen 107 hastalık serisinde, yapılan kolonoskopik incelemede kolorektal karsinom oranı \%7,4, inflamatuvar barsak hastalığı \%9,3 olarak bulunmuş, \% 26,1'inde kolona ait patoloji tespit edilmemiştir. Benzer çalışmalara göre çok yüksek seviyede, hastaların \%36,4'ünde, iskemik kolit saptanmıştır (7). Acil servise başvuran ve kolon duvar kalınlığ saptanan 150 hastalık başka bir seride ise kolonoskopik incelemede patoloji saptanma oranı \%64 olurken sadece 12 hastada kitle lezyonu saptanmıştır (8). Nicholson ve arkadaşlarının kolon duvar kalınlığı-kolonoskopik bulgular ilişkisinin değerlendirildiği 94 hastalık çalışmada ise hastaların sadece \%11'inde normal bulgular saptanırken, \%26'sinda adenokarsinom, \%25'inde adenom tanısı konulmuştur (9). Vakaların yarısından fazlasında malign veya premalign lezyon saptanmış olup biz çalışmamızda bu oranı \%60'lar seviyesinde bulduk.

Sonuç olarak, abdominal görüntüleme esnasında rastlantısal olarak bulunan kolon duvar kalınlaşması, özellikle hasta yaşı 50'nin üzerinde ve Hb düzeyi $12 \mathrm{mg} / \mathrm{dL}$ 'nin altında ise klinisyen öncelikle maligniteden şüphelenmelidir. Ileumda saptanan duvar kalınlaşması daha genç yaş grubunda saptanmakla birlikte Crohn hastalığı açısından mutlaka değerlendirilmeli, kolonoskopi ile birlikte mutlaka ileum entübasyonu yapılmalıdır. Aksine, üst GIS'de saptanan duvar kalınlaşması daha ziyade benign durumlarda karşımıza çıkmaktadır, hastanın $\mathrm{Hb}$ düzeyi ve yaşı bize klinik şüphe konusunda yol gösterici olabilir.

\section{KAYNAKLAR}

1. Macari M, Balthazar EJ. CT of bowel wall thickening: significance and pitfalls of interpretation. AJR Am J Roentgenol 2001;176:1105-16.

2. Cai Q, Baumgarten DA, Affronti JP, et al. Incidental findings of thickening luminal gastrointestinal organs on computed tomography: an absolute indication for endoscopy. Am J Gastroenterol 2003;98:1734-37.

3. Karim MS, Miranda MC, Shamma'a JM, et al. Utility of upper endoscopy and colonoscopy in evaluating gastrointestinal luminal wall thickening found on computed tomography. W V Med J 2010;106:16-9.

4. Tellez-Avila FI, García-Osogobio S, Chavez-Tapia NC, et al. Utility of endoscopy in patients with incidental gastrointestinal luminal wall thickening detected with CT. Surg Endosc 2009;23:2191-6.

5. Bleibel W, Guerrero JE, Kim S, et al. The clinical significance of incidental computer tomography finding of gastrointestinal luminal wall thickening as evaluated by endoscopy. Dig Dis Sci 2007;52:1709-12.

6. Moraitis D, Singh P, Jayadevan R, Cayten CG. Colonic wall thickening on computed tomography scan and clinical correlation. Does it suggest the presence of an underlying neoplasia? Am Surg 2006;72:269-71.

7. Wolff JH, Rubin A, Potter JD, et al. Clinical significance of colonoscopic findings associated with colonic thickening on computed tomography: is colonoscopy warranted when thickening is detected? J Clin Gastroenterol 2008;42:472-5.

8. Eskaros S, Ghevariya V, Diamond I, Anand S. Correlation of incidental colorectal wall thickening at CT compared to colonoscopy. Emerg Radiol 2009;16:473-6.

9. Nicholson BD, Hyland R, Rembacken BJ, et al. Colonoscopy for colonic wall thickening at computed tomography: a worthwhile pursuit? Surg Endosc 2011;25:2586-91. 